\title{
Decolorization of synthetic Coralene Violet 3R and Disperse Blue 2BL azo dyes using photoactive Calcium Aluminate nanoparticle in presence of sunlight
}

\author{
Yogendra Kambalagere ${ }^{1}$, Bhavya Channappa, Kittappa M Mahadevan², Madhusudhana Narayanappa
}

\begin{abstract}
The photocatalytic efficiency of the prepared Calcium aluminate $\left(\mathrm{CaAl}_{2} \mathrm{O}_{4}\right)$ nanoparticle was investigated against color induced by Coralene Violet 3R and Disperse Blue 2BL dyes. The $\mathrm{CaAl}_{2} \mathrm{O}_{4}$ nanoparticle was prepared by a simple solution combustion method and the average crystallite size was determined by XRD and SEM studies. Experiments were conducted to determine the influencing parameters of dye degradation such as catalyst dosage, solution concentration and $\mathrm{pH}$ of dye solution. The treatment with prepared calcium aluminate $\left(\mathrm{CaAl}_{2} \mathrm{O}_{4}\right)$ nanoparticle was proved to be effective in removing the color of $87.94 \%(0.3 \mathrm{~g} / 100 \mathrm{ml}$ catalyst dose, $\mathrm{pH} 3)$ and $79.82 \%(0.6 \mathrm{~g} / 100 \mathrm{ml}$ catalyst dose, $\mathrm{pH} 7)$ for Coralene Violet $3 \mathrm{R}$ and Disperse Blue 2BL in aqueous medium at $30 \mathrm{ppm}$ concentration of dyes. Thus, the $\mathrm{CaAl}_{2} \mathrm{O}_{4}$ nanoparticle was found to be more effective to degrade Coralene Violet $3 \mathrm{R}$ dye in presence of sunlight in a relatively short interval of time.
\end{abstract}

Keywords - Azo dye, $\mathrm{CaAl}_{2} \mathrm{O}_{4}$, Coralene Violet 3R, Catalyst, Disperse Blue 2BL, Nanoparticle, Azo dyes.

\section{INTRODUCTION}

$\mathrm{T}_{\mathrm{r}}^{\mathrm{H}}$ HE textile industry effluent comprises of various recalcitrant agents such as dye, sizing agents and dying aid [1] which are used for dying process. Among the dyes used in these industries, the azo dyes represent the largest class of synthetic dyes which constitute about $50 \%$ of the annual world dye production (approximately 700,000 tons) [2] and about $10-15 \%$ of the dye stuff lost in effluents during textile dyeing process [3].

On discharging to the environment, without proper treatment of these effluents can harm the biological life due to their toxicity, carcinogenicity, and due to high COD load $[4,5]$. There are conventional, physical and biological treatment methods are being studied for the treatment of textile wastewater but still found to be ineffective. The techniques such as reverse osmosis, nano-filtration, electrolysis, ozonization, incineration, ion exchange membrane filtration, and adsorption by activated carbon are

Yogendra Kambalagere ${ }^{1}$ Assistant Professor, Department of P. G. Studies and Research in Environmental Science, Kuvempu University, Jnana Sahyadri, Shankaraghatta-577451, Shimoga, Karnataka, India

Kittappa M Mahadevan ${ }^{2}$ Professor, Department of P. G. Studies and Research in Chemistry, Kuvempu University, Jnana Sahyadri, Shankaraghatta-577451, Shimoga, Karnataka, India however, expensive or are not easily adaptable to the large scale $[6,7]$.

Nevertheless, the nanocatalysts have been widely used in water treatment as it increases the catalytic activity at the surface due to their special characteristics of having higher surface area with shape dependent properties [8]. Recently in the field of nanotechnology, the photocatalytic degradation of organic pollutants mediated by semi-conductor nanoparticle provides an attractive alternative for the purification and treatment of colored waste water [9]. Search for economical ways to remove organic contaminants prompted the exploration of heterogeneous photocatalyst assisted oxidation methods, which shown complete mineralization of organic contaminants [7].

There are nanoparticles which are reported to degrade the number of dyes and textile effluents are, Pouretedal et al., (2010), reported the $\mathrm{CeO}_{2}$ as an effective catalyst against Methylene Blue in presence of natural sunlight, prepared by precipitation method using Cerium (IV) nitrate as the starting material [10]. Abdullah et al., (2010) studied the photo degradation of Rhodamine 6G and Phenol red by synthesized Titanium dioxide $\left(\mathrm{TiO}_{2}\right)$ by a solution gel method under solar irradiation [11]. Metal oxide nanoparticle like calcium zincate $\left(\mathrm{CaZnO}_{2}\right)$, zinc oxide $(\mathrm{ZnO})$, and composites of zinc oxide were also found to degrade dyes such as Coralene Dark Red 2B, Acid Orange 7, and Coralene Red F3BS respectively $[6,12,13]$.

Hence keeping in view of the advantages of photocatalytic degradation and in continuation of our investigation to identify more efficient nanoparticle for the degradation of industrial dyes, in the present work we are focused on the degradation of Coralene Violet $3 \mathrm{R}$ and Disperse Blue 2BL, using the prepared $\mathrm{CaAl}_{2} \mathrm{O}_{4}$ nanoparticle [14] as a photocatalyst in the presence of sunlight. In this study, some parameters such as catalyst dosage, varying dye concentration and $\mathrm{pH}$ of the dye solution were systematically investigated.

\section{MAterials AND Methods}

The commercially available water soluble azo dyes Coralene Violet $3 \mathrm{R}\left(\lambda_{\max } 480 \mathrm{~nm}\right)$ and Disperse Blue $2 \mathrm{BL}\left(\lambda_{\max }\right.$ $642 \mathrm{~nm}$ ) were obtained from Colortex Limited, Surat, Gujrat (Figure 1 and 2). The chemicals like Calcium nitrate (Ca $\left.\left(\mathrm{NO}_{3}\right)_{2} \cdot 4 \mathrm{H}_{2} \mathrm{O}\right) \quad(99 \%$, A. R.), Aluminium nitrate $\mathrm{Al}$ $\left(\mathrm{NO}_{3}\right)_{3} .9 \mathrm{H}_{2} \mathrm{O}$ (99\%, A.R.), Acetamide $\left(\mathrm{CH}_{3} \mathrm{CONH}_{2}\right)(99 \%$, 
A.R.), were obtained from Hi-Media Chemicals, Mumbai. The UV-VIS single beam spectrophotometer-119 (Systronics) was used for recording absorbance at $\lambda_{\max }$. Later the absorbance was recorded in UV-VIS spectrophotometer 169 (Systronics).

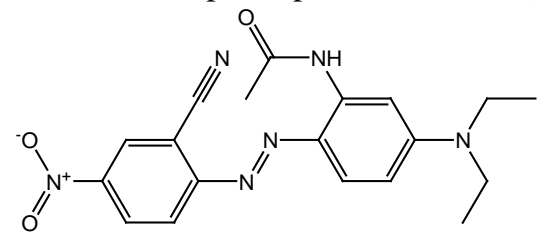

Fig. 1 Chemical structure of Coralene Violet 3R<smiles>Nc1c(N=Nc2ccc(-c3ccc(/N=N/c4cc([N+](=O)[O-])c5ccccc5c4N)cc3)cc2)cc([N+](=O)[O-])c2ccccc12</smiles>

Fig. 2 Chemical structure of Disperse Blue 2BL

\section{Synthesis Of Calcium Aluminate Nanoparticle}

The calcium aluminate nanoparticle was prepared by solution combustion method, using procured Calcium nitrate, Aluminium nitrate, and Acetamide (as fuel). Stoichiometric amounts of Calcium nitrate, Aluminium nitrate, and fuel Acetamide were calculated using the total oxidizing and reducing valences of the compounds which serve as numerical coefficients for stoichiometric balance. Initially $\mathrm{Ca}$ $\left(\mathrm{NO}_{3}\right)_{2} \cdot 4 \mathrm{H}_{2} \mathrm{O}(6.49 \mathrm{~g})$ and $\mathrm{Al}\left(\mathrm{NO}_{3}\right)_{3} \cdot 9 \mathrm{H}_{2} \mathrm{O}(20.63 \mathrm{~g})$ were dissolved in minimum quantity of water along with Acetamide (5.90 g) in a silica crucible. The crucible was introduced into the muffle furnace which was preheated to $600^{\circ}$ C. The solution boils and undergoes dehydration followed by decomposition along with the release of certain amounts of gases it froths and swells forming foam which ruptures with a flame. The product formed after combustion is a voluminous and foamy $\mathrm{CaAl}_{2} \mathrm{O}_{4}$. The combustion product thus, obtained is crushed in a mortar to make it amorphous. Hence the total mass obtained by the synthesis of the nanoparticle is 4.34g. According to the propellant chemistry, the following reaction takes place during combustion [14].

$$
\begin{gathered}
11 \mathrm{Ca}\left(\mathrm{NO}_{3}\right)_{2}+22 \mathrm{Al}\left(\mathrm{NO}_{3}\right)_{3}+40 \mathrm{CH}_{3} \mathrm{CONH}_{2} \rightarrow 11 \mathrm{CaAl}_{2} \mathrm{O}_{4} \\
+80 \mathrm{CO}_{2}+100 \mathrm{H}_{2} \mathrm{O}+64 \mathrm{~N}_{2}
\end{gathered}
$$

\section{Characterization Of Calcium Aluminate}

XRD analysis was carried out on fresh sample to assess the purity of the expected phases and the degree of crystallization, i.e., size, composition and crystal structure. XRD was performed by Rigaku diffractometer using $\mathrm{Cu}-\mathrm{K}_{\alpha}$ radiation $(1.5406 \AA)$ in a $\theta-2 \theta$ configuration. The XRD pattern of the prepared $\mathrm{CaAl}_{2} \mathrm{O}_{4}$ nanoparticle was as shown in fig. 3 .

According to the Debye-Scherrer's formula

$(\mathrm{D}=\mathrm{K} \lambda /(\beta \cos \theta)$,

Where $\mathrm{K}$ is the Scherrer's constant,

$\lambda$ the X-ray wavelength, $\beta$ is the peak width at half-maximum and $\theta$ is the Bragg diffraction angle),

So the average crystallite size $\mathrm{D}$ is $42 \mathrm{~nm}$.

The SEM images (fig. 4) of prepared $\mathrm{CaAl}_{2} \mathrm{O}_{4}$ nanoparticle have shown the typical texture and morphology. SEM images obtained were depicted that the synthesized nanoparticle were crystal like structures with sharp edges.

The absorbance spectrum of synthesized $\mathrm{CaAl}_{2} \mathrm{O}_{4}$ was recorded using UV-VIS spectrophotometer (Ocean Optics DH-2000) over the wavelength range 200-1200nm. The band gap energy of the $\mathrm{CaAl}_{2} \mathrm{O}_{4}$ nanoparticle was calculated using the following simple conversion equation. The band gap equation is calculated using the Planck's equation as follows.

$\mathrm{E}=\mathrm{hC} / \lambda$,

$\mathrm{h}=$ Planck's constant,

$\mathrm{C}=$ Velocity of light,

$\lambda=$ wavelength,

$\mathrm{h}=4.135 \times 10^{-15} \mathrm{eV}$,

$\mathrm{C}=3 \times 10^{8} \mathrm{~m} / \mathrm{s}$,

$\lambda=--\times 10^{-9} \mathrm{~nm}$

Band gap energy $(\mathrm{eV})=4.135 \times 10^{-15} \mathrm{eV} \times 3 \times 10^{8} \times 10^{9}$

Band gap energy $(\mathrm{eV})=1240 /$ wavelength $(\mathrm{nm})$.

The band gap energy of $\mathrm{CaAl}_{2} \mathrm{O}_{4}$ particle was $2.7 \mathrm{eV}$. The UV-absorbance of synthesized $\mathrm{CaAl}_{2} \mathrm{O}_{4}$ presented in fig.5.

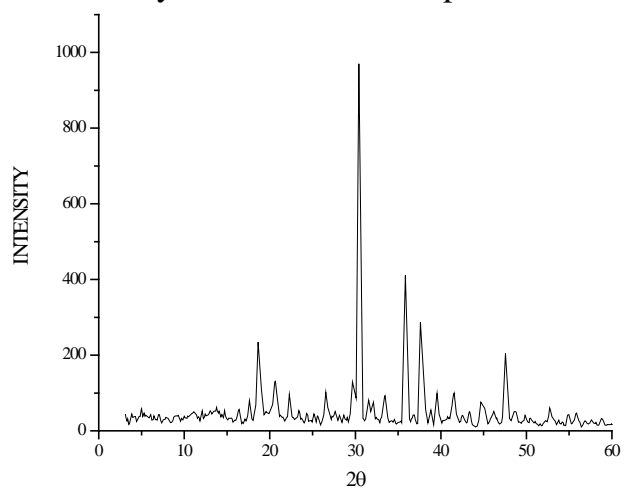

Fig. $3 \mathrm{XRD}$ of the synthesized $\mathrm{CaAl}_{2} \mathrm{O}_{4}$

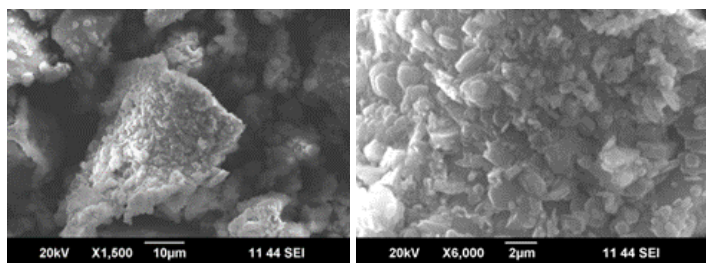

Fig. 4 SEM micrographs of synthesized $\mathrm{CaAl}_{2} \mathrm{O}_{4}$

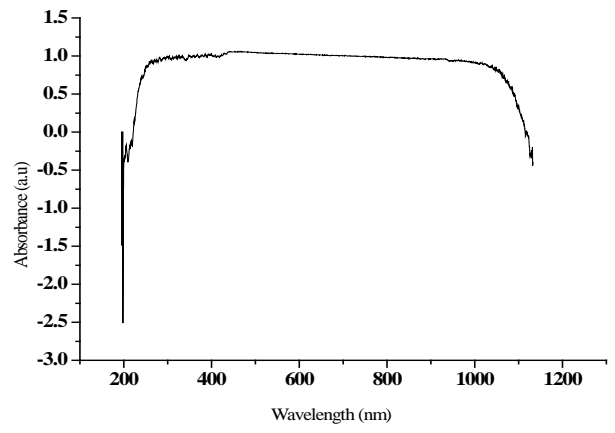

Fig. $5 \mathrm{UV}$-absorption spectra of synthesized $\mathrm{CaAl}_{2} \mathrm{O}_{4}$ 


\section{EXPERIMENTAL PROCEDURE}

The UV-VIS spectrophotometer 119 (Systronics) was used for the determination of absorbance. The $\lambda_{\max }$ value of Coralene Violet 3R and Disperse Blue 2BL was found to be $480 \mathrm{~nm}$ and $642 \mathrm{~nm}$ respectively. The photocatalytic experiments were carried out under direct sunlight. The known concentration of dye solutions were prepared by dissolving 30mg of Coralene Violet 3R and Disperse Blue 2BL separately in $1000 \mathrm{ml}$ of double distilled water and investigated for its decolorization in the presence of Calcium aluminate nanoparticle at different catalyst dosages and $\mathrm{pH}$ levels. Initially, $10 \mathrm{ml}$ of $30 \mathrm{mg} / \mathrm{L}$ dye samples were tested with different catalyst dosage (from $0.01 \mathrm{~g}$ to $0.1 \mathrm{~g}$ ) in the presence of direct sunlight. After the photocatalytic decolorization, the extent of decolorization was estimated by recording absorbance of the dye solution using UV-VIS spectrophotometer 169 in order to get the optimum catalyst dosage. The experiments were repeated at different $\mathrm{pH}$ levels (from 2 to 11) for the $100 \mathrm{ml}$ of same standard dye solutions with the optimum catalyst dose.

The percentage of degradation was determined by using the following equation,

The percentage of decolorization,

$\mathrm{D}=\left(\left(\mathrm{A}_{0}-\mathrm{A}_{\mathrm{t}}\right) \div \mathrm{A}_{0}\right) \times 100$

Where, $A_{0}$ is the initial absorbance of the dye solution

$A_{t}$ is absorbance at time interval ' $t$ ' i.e., after 120 minutes.

\section{Mechanism Of The Photocatalytic Degradation}

The mechanism of photocatalytic activity of nanoparticle can be predicted as below.

Step-1: Under sunlight irradiation, nanoparticle molecules get excited and transfer electrons to the conduction band.

$$
\mathrm{CaAl}_{2} \mathrm{O}_{4}+\mathrm{h} v \rightarrow\left(\mathrm{e}_{\mathrm{CB}}^{-}+\mathrm{h}^{+}{ }_{\mathrm{VB}}\right)
$$

Step-2: An electron in the conduction band of the nanoparticle can reduce molecular oxygen and produce the super oxide radical.

$$
\mathrm{e}_{\mathrm{CB}}^{-}+\mathrm{O}_{2} \rightarrow \mathrm{O}_{2}^{--}
$$

Step-3: Molecular oxygen, adsorbed on the surface of the photocatalysts prevents the hole-electron pair recombination process. Recombination of hole-electron pair decreases the rate of photocatalytic degradation. This radical may form hydrogen peroxide or organic peroxide in the presence of oxygen and organic molecule.

$$
\begin{aligned}
& \mathrm{H}_{2} \mathrm{O}+\mathrm{O}_{2}{ }^{--} \rightarrow \mathrm{OOH}^{\cdot}+\mathrm{OH}^{-} \\
& 2 \mathrm{OOH}^{\circ} \rightarrow \mathrm{O}_{2}+\mathrm{H}_{2} \mathrm{O}_{2} \\
& \mathrm{O}_{2}^{-{ }^{--}}+\text {dye } \rightarrow \text { dye-OO }
\end{aligned}
$$

Hydrogen peroxide can be generated in another path.

$$
\mathrm{OOH}^{*}+\mathrm{H}_{2} \mathrm{O}+\mathrm{e}_{\mathrm{CB}}^{-} \rightarrow \mathrm{H}_{2} \mathrm{O}_{2}+\mathrm{OH}^{-}
$$

Step-4: Hydrogen peroxide can form hydroxyl radicals which are powerful oxidizing agents.

$$
\begin{aligned}
& \mathrm{H}_{2} \mathrm{O}_{2}+\mathrm{e}^{-} \mathrm{CB} \rightarrow \mathrm{OH}^{-}+\mathrm{OH}^{-} \\
& \mathrm{H}_{2} \mathrm{O}_{2}+\mathrm{O}_{2}^{--} \rightarrow \mathrm{OH}^{-}+\mathrm{OH}^{-}+\mathrm{O}_{2}
\end{aligned}
$$

Step-5: The radicals produced are capable of attacking dye molecules and degrade them.

$$
\mathrm{OH}^{*} / \mathrm{O}_{2}^{-} / \mathrm{CaAl}_{2} \mathrm{O}_{4}{ }^{-+}+\text {dye } \rightarrow \text { Dye degradation }
$$

\section{RESUlTS AND DISCUSSION}

\section{A. Optimum Catalyst Dose}

In order to study the effect of catalyst load, calcium aluminate dosage was varied from $0.01 \mathrm{~g}$ to $0.1 \mathrm{~g}$ for $30 \mathrm{mg} / \mathrm{L}$ of Coralene Violet 3R and Disperse Blue 2BL dye solutions and the results are presented in Fig. 6. On exposure of reaction volume to sunlight after adding the catalyst, the dye color started to fade by showing the visible signs of decolorization. The highest degradation $85.52 \%$ (C. Violet $3 \mathrm{R}$ ) and $78.82 \%$ (D. Blue 2BL) and was recorded for $0.3 \mathrm{~g} / 100 \mathrm{ml}$ and $0.6 \mathrm{~g} / 100 \mathrm{ml}$ of catalyst which was sufficient to degrade Coralene Violet 3R and Disperse Blue 2BL dye solutions within 120 minutes.
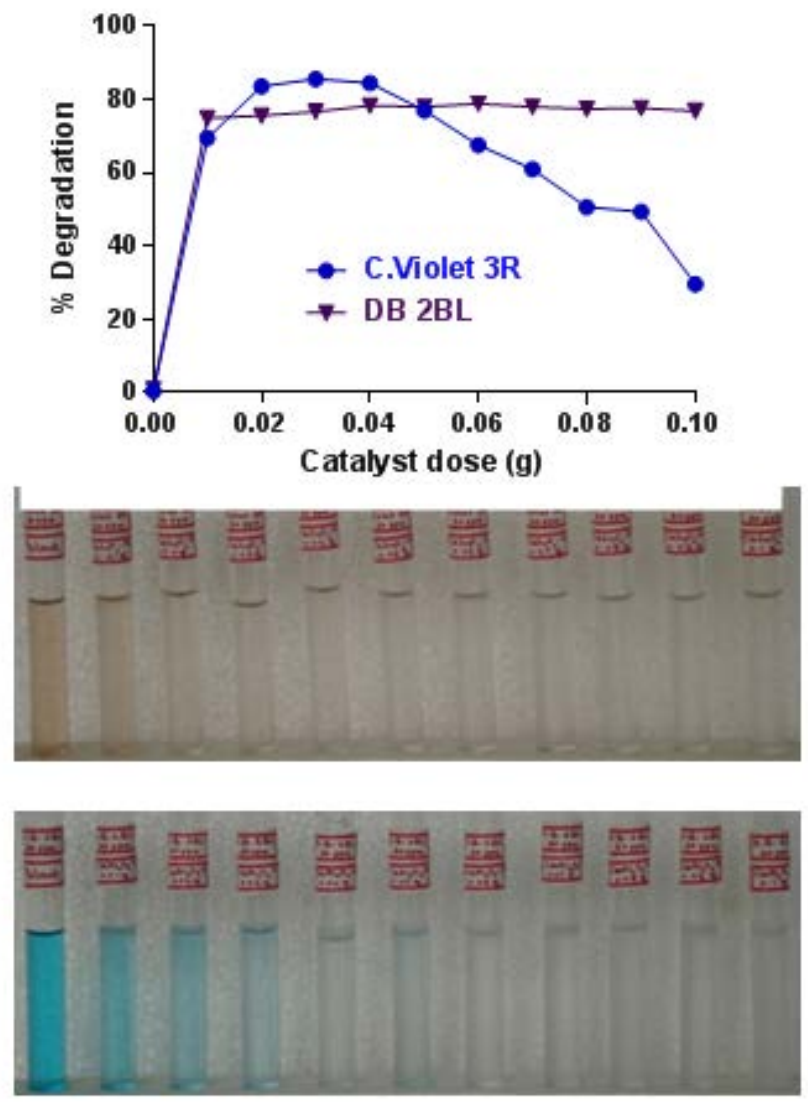

Fig. 6 Effect of catalyst dose on the decolorization of C.Violet 3R and D.Blue 2BL dye solutions at concentration $30 \mathrm{mg} / \mathrm{L}$, at $\mathrm{pH} 7$ with respect to time interval of 120 minutes

\section{B. Optimum $\mathrm{pH}$}

The photocatalytic experiments were conducted at different $\mathrm{pH}$ from 2 to 11 by keeping the catalyst dose constant i.e., $0.3 \mathrm{~g} / 100 \mathrm{ml}$ and $0.6 \mathrm{~g} / 100 \mathrm{ml}$ for $30 \mathrm{mg} / \mathrm{L}$ of C. Violet $3 \mathrm{R}$ and D. Blue 2BL dye solutions. $\mathrm{pH}$ of the solution was adjusted by using $0.2 \mathrm{~N} \mathrm{HCl} / \mathrm{NaOH}$ solution and the results are presented in Fig. 7. On exposure of reaction volume to sunlight, the highest degradation $87.94 \%$ at $\mathrm{pH} 3$ and $79.82 \%$ at $\mathrm{pH} 7$ was recorded for C. Violet $3 \mathrm{R}$ and D. Blue 2BL respectively. 

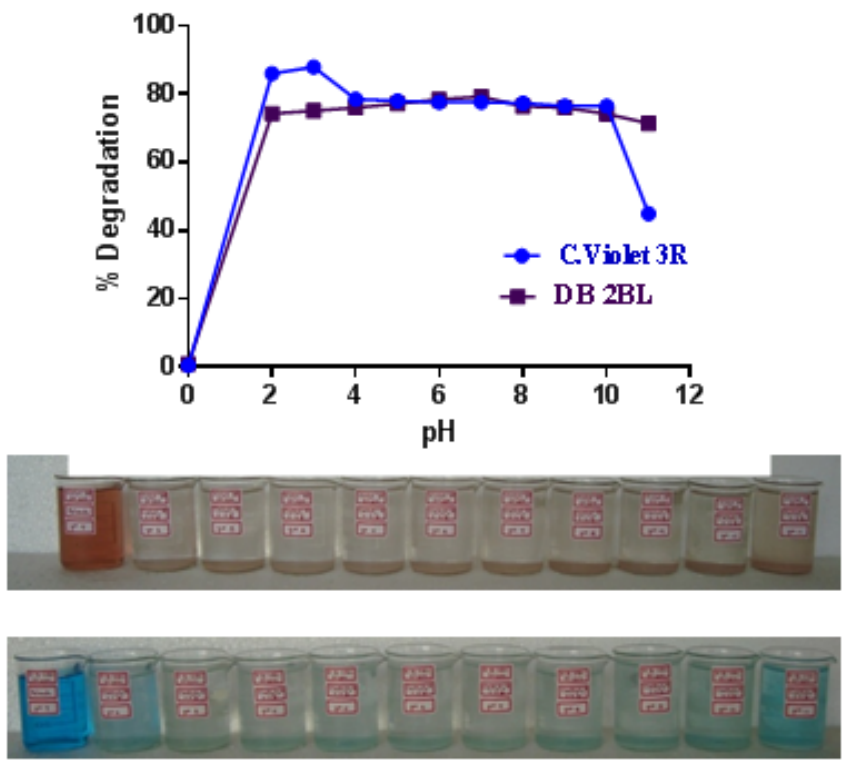

Fig. 7 Effect of $\mathrm{pH}$ on the decolorization of C.Violet 3R and D.Blue $2 \mathrm{BL}$ dye solutions at concentration $30 \mathrm{mg} / \mathrm{L}$, with respect to time interval of 120 minutes.

\section{Degradation efficiency of $\mathrm{CaAl}_{2} \mathrm{O}_{4}$ at different dye} concentrations

To study the effect of initial dye concentration on the photocatalytic efficiency of $\mathrm{CaAl}_{2} \mathrm{O}_{4}$ nanoparticle the initial dye concentrations were varied to 60ppm, 90ppm and 120ppm and experiments were conducted at optimum catalyst dosage and $\mathrm{pH}$. The highest degradation of $87.94 \%$ and $79.82 \%$ was recorded for the concentration of 30ppm Coralene navy Blue 3G and Coralene Violet 3R dye solution respectively. Results shown in fig. 8 indicate the decreased degradation efficiency with increase in the concentration of dye solutions. Compared to C.Violet 3R, percent degradation was greatly reduced for D.Blue 2BL with increase in the concentration of the dye solution.
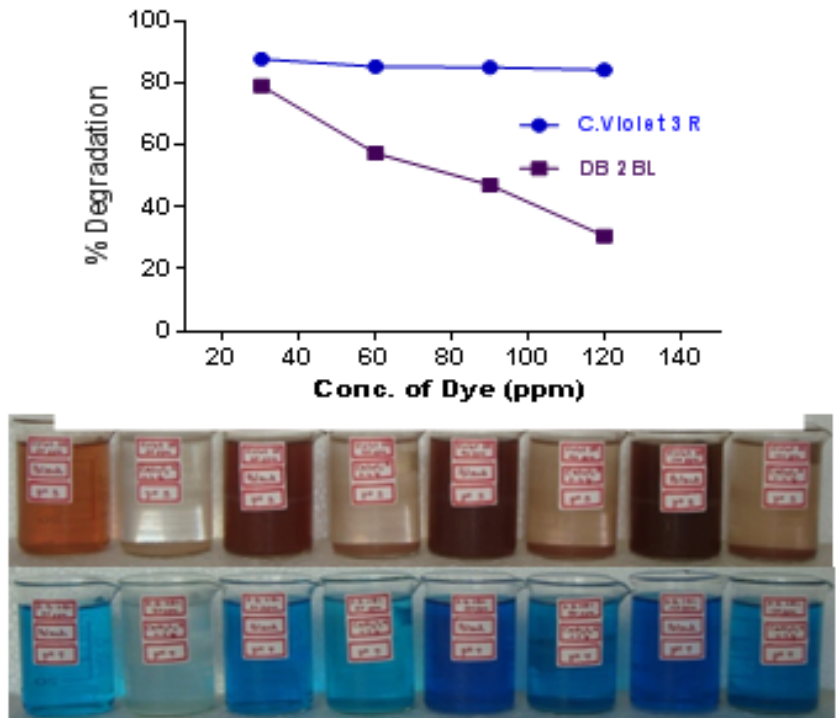

Fig. 8 Effect of optimum catalyst dose and $\mathrm{pH}$ on the decolorization of C.Violet 3R and D.Blue 2BL dye solutions at different concentrations (30ppm, 60ppm, 90ppm and 120ppm), with respect to time interval of 120 minutes

\section{CONCLUSION}

The photocatalytic degradation of Coralene Violet 3R and Disperse Blue 2BL dye were studied by using $\mathrm{CaAl}_{2} \mathrm{O}_{4}$ nanoparticle in presence of sunlight. The results show that the maximum of $87.94 \%(0.3 \mathrm{~g} / 100 \mathrm{ml}$ catalyst dose) and $78.82 \%$ $(0.6 \mathrm{~g} / 100 \mathrm{ml}$ catalyst dose) degradation efficiency was achieved in 120minutes. Further it was also noticed that the extent of degradation was found to depend on concentration of the $\mathrm{CaAl}_{2} \mathrm{O}_{4}, \mathrm{pH}$ of the dye solutions and the dye concentration (30ppm, 60ppm, 90ppm and 120ppm). Thus, based on the degradation results, it was concluded that, since the degradation was achieved in presence of sunlight, the present protocol can be adapted to the large scale industrial decoloration processes and may reduce the water pollution to a certain extent.

\section{REFERENCES}

[1] W. Somasiri, W. Ruan, L. Xiufen, and C. Jian, “ Decolourization of textile wastewater containing acid dyes in UASB reactor system under mixed anaerobic granular sludge", Electron. J. Environ. Agric. Food Chem, vol. 5, no. 1, pp. 1224-1234, 2006.

[2] Niyaz Mohammad Mahmoodi, Mokhtar Arami, and Nargess Yousefi Limaee, "Photocatalytic Degradation of Triazinic Ring-Containing Azo Dye (Reactive Red 198) by Using Immobilized $\mathrm{TiO}_{2}$ Photoreactor: Bench Scale Study”, Journal of hazardous materials, vol. 133, pp.113118, 2006.

http://dx.doi.org/10.1016/j.jhazmat.2005.09.057

[3] Niamh Kirby, Roger Marchant, and Geoffrey McMullan, “ Decolourisation of synthetic textile dyes by Phlebia tremellosa. FEMS Microbiology Letters”, vol. 188, no. 1, pp. 93-96, 2000. http://dx.doi.org/10.1111/j.1574-6968.2000.tb09174.x

[4] N. Madhusudhana, K. Yogendra and K. M. Mahadevan, " Photocatalytic decolourization of textile effluent by using metal oxide nanoparticle" Journal of Science and Arts, vol. 3, no. 24, pp. 303-318, 2013.

[5] Hamid Reza Kariminiaae Hamedaani, Akihiko Sakurai, and Mikio Sakakibara, "Decolorization of synthetic dyes by a new manganese peroxidase-producing white rot fungus”, Dyes and Pigments, vol. 72, no. 2, pp. 157-162, 2007. http://dx.doi.org/10.1016/j.dyepig.2005.08.010

[6] K. Yogendra, K.M. Mahadevan, Suneel Naik, N. Madhusudhana, "Photocatalytic activity of synthetic ZNO composite against Coralene red F3BS dye in presence of solar light”, International Journal of Environmental Sciences,. Vol. 1, no. 5, pp. 839-846, 2011.

[7] G.B. Saupe, Y. Zhao, J. Bang, N.R. Yesu, G.A. Carballo, R. Ordonez, and T. Bubphamala, "Evaluation of a new porous titanium-niobium mixed oxide for photocatalytic water decontamination”, Microchemical Journal, vol. 81, no. 1, pp. 156-162, 2005.

http://dx.doi.org/10.1016/j.microc.2005.01.002

[8] Prachi, Pranjali Gautam, Deepa Madathil, and A. N. Brijesh Nair, "Nanotechnology in Waste Water Treatment: A Review", International Journal of Chem Tech Research, vol. 5, no. 5, pp. 2303-2308, 2013.

[9] Xie Quan, Shuo Chen, Jing Su, Jingwen Chen, and Guohua Chen, "Synergic degradation of 2,4-D by integrated photo- and electrochemical catalysis on a Pt doped $\mathrm{TiO}_{2} / \mathrm{Ti}$ electrode", Separation and Purification Technology, vol. 34, no. 1, pp. 73-79, 2004. http://dx.doi.org/10.1016/S1383-5866(03)00177-1

[10] H.R. Pouretedal, A. Kadkhodaie, "Synthetic CeO2 Nanoparticle Catalysis of Methylene Blue Photodegradation: Kinetics and Mechanism”, Chinese Journal of Catalysis, vol. 31, no. 11. pp.13281334, 2010. http://dx.doi.org/10.1016/S1872-2067(10)60121-0

[11] M. Abdullah Asiri, S. Muhammed Al Amoudi, A. Tariq Al Talhi, and D. Abdullah Al Talhi, "Photodegradation of Rhodamine 6G and phenol red by nanosized $\mathrm{TiO}_{2}$ under solar irradiation", Journal of Saudi Chemical Society”, vol. 15, no. 2. pp. 121-128, 2011. http://dx.doi.org/10.1016/j.jscs.2010.06.005

[12] N. Madhusudhana, K. Yogendra, K.M. Mahadevan, and Suneel Naik, "Photocatalytic degradatiopn of degradation of Coralene Dark Red 2B azo dye using Calcium zincate nanoparticle in presence of natural 
sunlight: An aid to Environmental remediation”, International Journal of Chemical Engineering and Applications, vol. 2, no. 4, pp. 301-305, 2011.

[13] N. Daneshvar, M.H. Rasoulifard, A.R. Khataee, and F. Hosseinzadeh, "Removal of C.I. Acid Orange 7 from aqueous solution by UV irradiation in the presence of ZnO nanopowder", J Hazard. Mater, vol. 143, no. 1-2, pp. 95-101, 2007. http://dx.doi.org/10.1016/j.jhazmat.2006.08.072

[14] N. Madhusudhana, K. Yogendra, and K. M. Mahadevan, "Photocatalytic Degradation of Violet GL2B Azo dye by using Calcium Aluminate Nanoparticle in presence of Solar light”, Research Journal of Chemical Sciences,. Vol. 2, no. 5, pp. 72-77, 2012.

Yogendra Kambalagere was born at Shimoga, Karnataka state, India on 1st June, 1971. He has obtained his Ph.D. in Environmental Science from Kuvempu University in 2000. M.Sc. degree in Environmental Science in the year 1994 from Kuvempu University and B.Sc. in Chemistry, Botany and Zoology in 1992 from Kuvempu University. He is working as ASSISTANT PROFESSOR in the Department of Post-graduate Studies and Research in Environmental science, Kuvempu University since 2007. He has also worked as Research Associate in a research project sponsored by National River Conservation Directorate, Ministry of Environment and Forests, Government of India. He has published 40 research articles in the field of environmental studies. His interest is in the areas of environmental chemistry particularly in the field of color degradation of dyes by using nano-sized semiconductor metal oxides. Dr.Yogendra K is a senior member for APCBEES, Member for International Association for Ecology (INTECOL), Indian Science Congress Association (ISCA) Kolkata, National Institute of Ecology (NIE) Jaipur, Editorial Advisory Board, International Journal of Environmental Sciences and Research (IJESR) India and International Scientific Academy of Engineering \& Technology (ISAET). Dr. Yogendra K has been awarded with Sir.M. Visweswaraih Parisara Ratna-2010 and Senior Scientist Award in the year 2010 and 2012 respectively. 